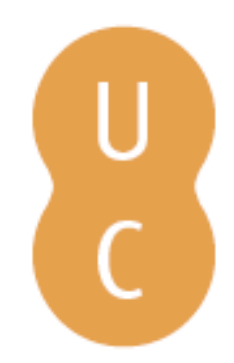

\title{
nombalina
}

\section{A seca como factor de risco ambiental no semiárido brasileiro}

Autor(es): $\quad$ Ramalho, Maria F. J. L.; Guerra, Antonio J. T.

Publicado por: Imprensa da Universidade de Coimbra; RISCOS - Associação

URL

persistente: URI:http://hdl.handle.net/10316.2/34873

DOI: $\quad$ DOI:http://dx.doi.org/10.14195/978-989-96253-3-4_72

Accessed : $\quad$ 26-Apr-2023 11:33:07

A navegação consulta e descarregamento dos títulos inseridos nas Bibliotecas Digitais UC Digitalis, UC Pombalina e UC Impactum, pressupõem a aceitação plena e sem reservas dos Termos e Condições de Uso destas Bibliotecas Digitais, disponíveis em https://digitalis.uc.pt/pt-pt/termos.

Conforme exposto nos referidos Termos e Condições de Uso, o descarregamento de títulos de acesso restrito requer uma licença válida de autorização devendo o utilizador aceder ao(s) documento(s) a partir de um endereço de IP da instituição detentora da supramencionada licença.

Ao utilizador é apenas permitido o descarregamento para uso pessoal, pelo que o emprego do(s) título(s) descarregado(s) para outro fim, designadamente comercial, carece de autorização do respetivo autor ou editor da obra.

Na medida em que todas as obras da UC Digitalis se encontram protegidas pelo Código do Direito de Autor e Direitos Conexos e demais legislação aplicável, toda a cópia, parcial ou total, deste documento, nos casos em que é legalmente admitida, deverá conter ou fazer-se acompanhar por este aviso.

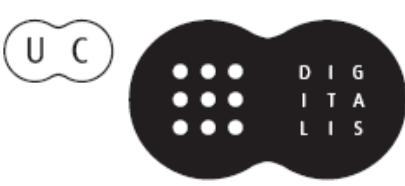



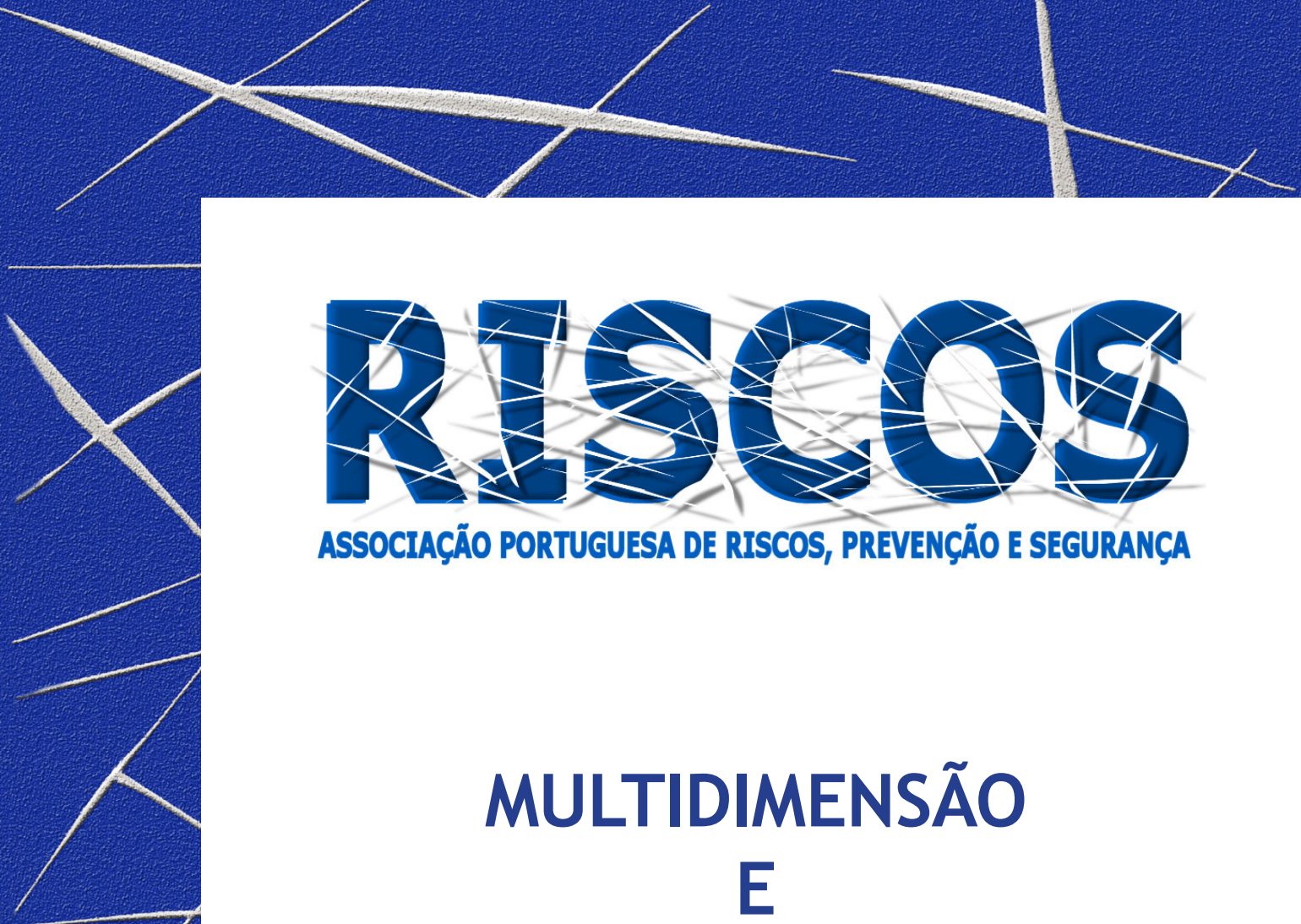

ASSOCIAÇÃO PORTUGUESA DE RISCOS, PREVENCCÃO E SEGURANÇA

MULTIDIMENSÃO

E
TERRITÓRIOS DE RISCO

III Congresso Internacional

I Simpósio Ibero-Americano

VIII Encontro Nacional de Riscos

Guimarães

2014 


\title{
A SECA COMO FATOR DE RISCO AMBIENTAL NO SEMIÁRIDO BRASILEIRO
}

\author{
Maria F.J.L. Ramalho \\ Departamento de Geografia, Universidade Federal do Rio Grande do Norte \\ mfjmaria@gmail.com
}

Antonio J. T. Guerra

Departamento de Geografia, Universidade Federal do Rio de Janeiro antonioguerra@gmail.com

\begin{abstract}
RESUMO
As áreas de clima quente e seco como a do Semiárido Brasileiro são vulneráveis às estiagens prolongadas e ao consequente impacto ambiental, com reflexo mais grave para o homem do campo. A maior seca dos últimos trinta anos, como foi noticiado em 2013, causou relevante repercussão nos reservatórios de água, a exemplo do Açude de Poços, localizado no município de Teixeira, no estado da Paraíba.

Este trabalho apresenta algumas considerações sobre o ambiente de impacto da seca onde se insere o referido Açude - um reservatório de água entre outros do Semiárido afetado pela estiagem. 0 objetivo da pesquisa nessa área é analisar a convivência do homem com a dinâmica natural, tendo em vista a imprevisibilidade do evento e o risco ambiental. Com base no método empírico e utilizando dados bibliográficos, cartográficos, de campo e de laboratório, atenta-se para os fatores de vulnerabilidade e potencialidade da região, tendo em conta a sazonalidade climática.
\end{abstract}

Palavras-chave: Semiárido Brasileiro; Sazonalidade Climática; Risco Ambiental.

\section{Introdução}

O fenômeno da sazonalidade climática do Semiárido Brasileiro, com períodos mais secos e períodos pouco úmidos, revela-se pelos subsequentes efeitos na fisionomia da paisagem e na vivência da população residente e usuária dos recursos naturais, entre os quais, a água, que se torna insuficiente ou abundante, conforme os respectivos períodos de estiagem e de chuva. Neste último, após as primeiras chuvas torrenciais, maior é a erosão, destacando-se principalmente o estado de degradação da cobertura vegetal. Tem-se aí um fator que pode instaurar uma realidade perversa, pois o risco natural de ocorrência de seca termina por associar-se à vulnerabilidade ambiental do meio afetado por condicionantes climáticos e pela interferência humana na cobertura vegetal e nos solos. Conforme Sá et al. (2010), as pesquisas realizadas em áreas do Semiárido Brasileiro "demonstram uma realidade de processos negativos sobre flora e fauna silvestre, bem como sua estreita ligação com a atuação do homem sobre o meio, principalmente sobre os solos, onde os processos erosivos se intensificam e constituem os indícios mais marcantes da desertificação." Assim, o efeito da dinâmica erosiva no processo de assoreamento dos mananciais tende a comprometer o tempo de permanência da água nos reservatórios, impossibilitando a disponibilidade do recurso hídrico no período crítico da estiagem, sendo exemplo disto o caso do açude de Poços. Com a pesquisa em tal área, esperase contribuir para o entendimento do significado da sazonalidade climática em ambientes do Semiárido favorecido pela açudagem.

\section{Caracterização geográfica e ambiental}

A área de estudo pertence ao sistema de relevo do Planalto da Borborema, onde se insere o maciço residual da Serra do Teixeira, com altitudes em torno de 750 metros, integrando o 
município de Teixeira, no qual se encontra a Comunidade de Poços e o Açude homônimo, localizado na interseção aproximada do paralelo 70 14' 42', ao sul do Equador, com o meridiano $37^{\circ}$ 12' 28' de longitude, a oeste de Greenwich (Fig. 1). Essa área também se inclui na do Polígono da Seca definida pelo Ministério da Integração Nacional (BRASIL, 2005).

De acordo com os estudos hidrológicos da CPRM (2005), o clima, conforme a Classificação de Köppen, é do tipo Aw'- quente úmido, com chuvas de verão e outono, e, na Classificação Bioclimática de Gausen, é do tipo 4ath - Tropical quente, de seca acentuada, com 7 a 8 meses secos. O regime pluviométrico é marcado pela distribuição irregular das chuvas, com índice que varia de $420 \mathrm{~mm}$ a $714 \mathrm{~mm}$, concentrando-se entre os quatro primeiros meses do ano $82 \%$ das chuvas. As temperaturas médias anuais estão entre $23^{\circ} \mathrm{C}$ e $24^{\circ} \mathrm{C}$ e a umidade relativa do ar em torno de $50 \%$.

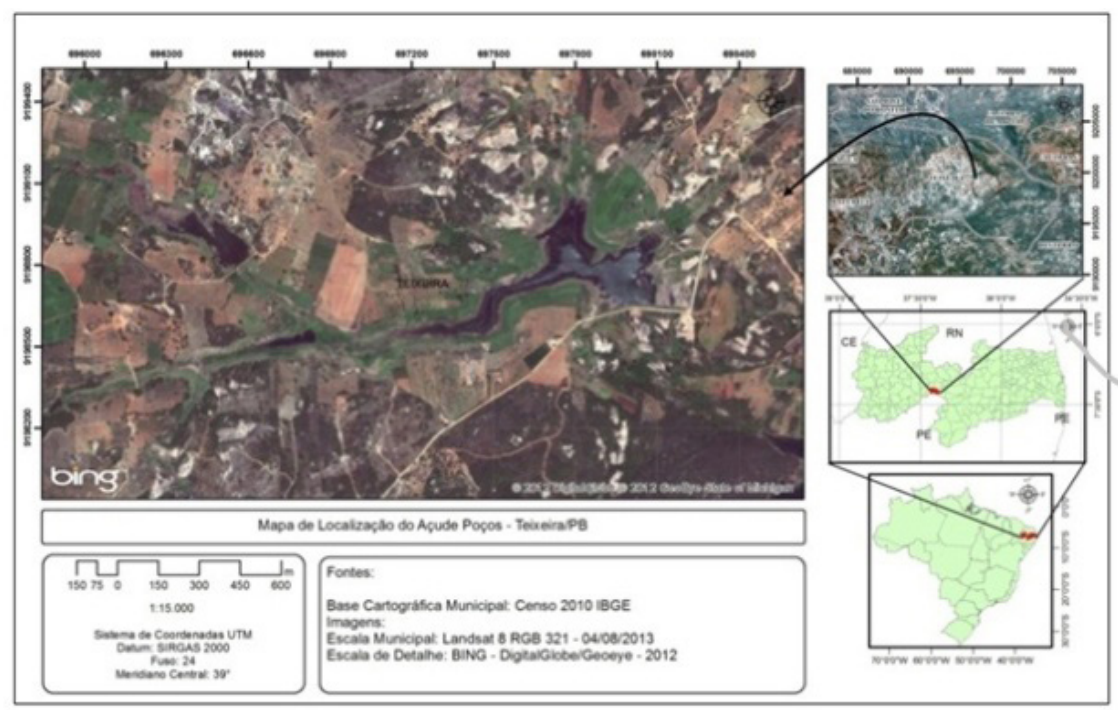

Fig. 1 - Localização da área de estudo

O predomínio das rochas cristalinas, a altitude e a localização geográfica explicam em parte a fisionomia da paisagem, onde a vegetação típica da região é representada pelo Bioma da Caatinga. A superfície elevada e as declividades acentuadas, que se diferenciam entre os compartimentos da Serra, favorecem o represamento de água em fundo de vale, como é o caso dos açudes da região, que, além de serem alimentados pelas águas pluviais, são também receptores do aporte de sedimentos levados pelas enxurradas ocasionais do período chuvoso. A drenagem superficial, de caráter intermitente, garante, no período das chuvas, o armazenamento de água nas represas.

\section{A Seca: um fenômeno natural}

A Seca no Semiárido Brasileiro tem sido entendida como um fenômeno natural decorrente de condições climáticas que afetam as fontes de água, o solo e a vegetação. 
Há cerca de aproximadamente 136 anos, de acordo com Baptista (1933), o Cônego Bernardo, Vigário de Teixeira e Deputado Provincial, comovido com os estragos da Seca de 1877 a 1879, que também atingia o povo de sua terra, dá início em 1878 à obra da represa de Poços, conforme projeto por ele mesmo idealizado.

Esse memorável Açude, de acordo com o mesmo autor, foi construído pelos próprios flagelados do referido evento, que, conforme Almeida (1993), foi uma seca de caráter destruidor, pelo alarmante índice de óbitos, estimado em torno de 500.000 vítimas. 0 histórico Açude, que se destaca no estado da Paraíba como uma das primeiras obras de combate à seca no Governo Imperial, foi exaurido com o impacto da Seca de 2013 .

Por se tratar de uma obra julgada necessária para as imprevisões das grandes estiagens, principalmente no sentido de manter as culturas, em torno da área, irrigadas, com a Seca dá-se a interrupção das atividades agrícolas, acarretando o aumento das privações econômicas pelas quais passa a população por causa da falta de água.

\section{O ambiente de impacto da Seca}

Considerando as condições de sazonalidade climática da região, atenta-se para uma análise empírica que avalia o ambiente de entorno do Açude de Poços, tendo em vista a importância das encostas, da cobertura vegetal e do solo.

As vertentes, que se apresentam como subunidades do sistema de relevo, constituem um dos ambientes de maior atenção nesse contexto. A declividade e a variedade heterométrica dos blocos rochosos que caracterizam o perfil das encostas influenciam no rigor do escoamento e condicionam não só a deposição de detritos em áreas preferenciais do terreno como também a retenção temporária de água, no período da chuva. De acordo com Ramalho (2013), o material que se acumula, conforme sua textura, mantém por mais tempo a umidade, possibilitando, assim, melhores condições para o desenvolvimento da vegetação. As proporções do teor de areia, teor de silte e teor de argila determinadas a partir da análise granulométrica, utilizandose o Método da Embrapa (2011), confirmam a tendência para a concentração de elementos finos, como silte e argila, nos locais de depósito, enquanto nos locais dos sedimentos em trânsito as proporções desses elementos aparecem com menores percentuais.

Neste aspecto, considerando a relação entre as causas e os efeitos das ações erosivas e deposicionais, tendo em conta a natureza dos fatores físicos da região, convém observar que, após o evento de uma seca prolongada e durante o chuvoso, a drenagem natural das vertentes tanto erode como inunda as baixadas junto com os detritos carreados pela dinâmica das enxurradas sobre a superfície desnuda.

Sendo a vegetação um dos fatores controladores da erosão, conforme muitos autores (Stocking e Elwell 1976; Evans, 1980; Thornes, 1980; Finney, 1984; Morgan, 1984; Guerra, 2009, 2010), entende-se que, conforme Ramalho (2009), com a alteração da cobertura vegetal do período seco e o uso do solo com as práticas de manejo não adequadas às condições de sustentabilidade do ambiente, há maiores tendências para o aumento das taxas erosivas, com efeitos consideráveis tanto para as áreas que perdem quanto para as que ganham sedimentos, tendo em conta a erosão acelerada que degrada o solo e ameaça o desempenho da açudagem, devido ao assoreamento. Neste sentido, tem-se diminuída a capacidade de o Açude armazenar um volume maior de águas pluviais e, com a escassez da chuva, a água represada apresenta-se insuficiente para atender à demanda hídrica do período da estiagem, à proporção que a evaporação e o cultivo irrigado se intensificam. 


\section{Conclusão}

Com a Seca, além da evaporação elevada e do déficit hídrico, há naturalmente as mudanças no aspecto da vegetação. Consequentemente, o solo se expõe à insolação e perde umidade, mostrando-se, no período do evento, ineficiente para uso agrícola. Com as alterações da cobertura vegetal, causadas tanto pela seca quanto pela intervenção do homem, acentua-se a vulnerabilidade à erosão, com risco de assoreamento de corpo d'água, como é o caso da represa de Poços. Combater a degradação da vegetação causada pelo homem, tendo em conta os condicionantes bioclimáticos do Semiárido, pode ser a forma mais eficaz para se ter amenizado o efeito da erosão acelerada e se vir a poder conservar por mais tempo a água nas fontes, além de se ter melhorada a qualidade da água dos mananciais afetada por agrotóxicos e fertilizantes químicos. Neste sentido, considera-se a importância de um planejamento ambiental com ações de gestão para o uso da água e também com alternativas de sustentabilidade para o uso do solo.

\section{Bibliografia}

Almeida, J. A. (1994) - A Paraíba e seus problemas. Brasília, Senado Federal/Fundação Casa de José Américo, $728 \mathrm{p}$.

Baptista, P. (1933) - O Cônego Bernardo. Rio de Janeiro, Civilização Brasileira, 211 p.

Brasil. Ministério da Integração Nacional. (2005) - Nova Delimitação do Semi-árido Brasileiro. Brasília, Secretaria de Políticas e Desenvolvimento Regional.

CPRM. Serviço Geológico do Brasil. (2005) - Projeto Cadastro de Fontes de Abastecimento por Água Subterrânea. Diagnóstico do Município de Teixeira, estado da Paraíba. Recife, CPRM/PRODEEM, 10 p.

EMBRAPA. Empresa Brasileira de Pesquisa Agropecuária. (2011) - Manual de Métodos de Análise de Solos. Rio de Janeiro, CNP, $230 \mathrm{p}$.

Evans, R. (1980) - Mechanics of water erosion and their spatial and temporal controls: an empirical viewpoint. In. Kirkby, M. J. , Morgan, R. P. C. (Eds.). Soil erosion. Cambridge, John Wiley and Sons Ltda., 1980. p. 109-128.

Finney, H. J. (1984) - The effects of crop cover on rainfall characteristics and splash detachment. Journal of Agricultural Engineering Research, 29, p. 337-334.

Guerra, A. J. T. (2009) - Processo Erosivo nas Encostas. In: A. J. T. Guerra e S. B. Cunha (Orgs.). Geomorfologia - Uma Atualização de Bases e Conceitos. Rio de Janeiro, Bertrand Brasil, p. 149 -209.

Guerra, A. J. T. (2010) - 0 início do processo erosivo. In: Guerra A. J. T.; Silva, A. S.; Botelho, R. G. M. (Org.). Erosão e conservação dos solos: conceitos, temas e aplicações. Rio de Janeiro, Bertrand Brasil. p.15-55.

Morgan, R. P. C. (1984) - Soil degradation and erosion as a result of agricultural practice. .In: Geomorphology and Soils. Editores: K. S. Richards; R. R. Arnett e S. Ellis. London, George Allen and Unwin, p. 370395.

Ramalho, M.F.J. L. (2009) - Considerações sobre o ambiente de rios represados: o caso do rio Piranhas-Açu no Rio Grande do Norte. Sociedade e Território, 21, p. 183-196.

Ramalho, M.F.J. L. (2013) - A fragilidade ambiental do nordeste brasileiro: o clima semiárido e as imprevisões das grandes estiagens. Sociedade e Território, 25, p. 104-116.

Sá, I. B. et al. (2010) - Desertificação no Semiárido brasileiro. Fortaleza, ICID, 18, p. 16-20.

Stocking, M. A. and Elwell, H. A. (1976) - Vegetation and erosion: a review. Scottish Geographical Magazine, 92, p. 93-101.

Thornes, J. B. (1980) - Erosional processes of running water and their spatial and temporal controls: a theoretical viewpoint. In: Kirkby, M. J., Morgan, R. P. C. (eds.). Soil erosion. New York, John Wiley and Sons, p. 129-182. 